\title{
Urban quality improvement programs in the Sustainable Urban Mobility Plan of Valencia (Spain)
}

\author{
M. T. Broseta \\ Departamento de Urbanismo, \\ Universidad Politécnica de Valencia, España
}

\begin{abstract}
The current challenge of Spanish town-planning is to change wrong land planning practices adopted in the past, based in extensive developments, without considering their environmental impacts. The environmental audits point to mobility as one of the main reasons of unsustainability.

Urban transport implanted nowadays generates high fossil fuel consumption and expensive management costs; it increases atmospheric and acoustic pollution and deteriorates the urban quality of life, regarding road safety, public health and increasing spaces for cars; it almost causes social exclusion and city barriers for disadvantaged groups.

At the beginning of 2000, Central Administration offered the proper tool for developing sustainable mobility policies in townships: Sustainable Urban Mobility Plans (SUMP), which some of the main cities of the country are promoting, as Getafe (2007), Segovia (2008), León (2009), Irún (2010), Salamanca and Córdoba (2011) Granada and Valencia (2013).

Valencia SUMP contents include several pedestrian programs to recover urban quality of life: old quarter mobility plan, main pedestrian itineraries project, urban centers development, 30Kmph-zones, superblocks design and safe pedestrian ways to schools and accessibility for disabled people.

The public participation plan is demonstrating that citizens are taking an interest in urban quality programs in Valencia; as far as they trust the local council investments revert to their city quality improvement, with a view to saving resources and creating economic and tourism assets that bring full employment.
\end{abstract}

Keywords: urban quality programs, sustainable urban mobility plans, SUMP, town-planning, Valencia. 


\section{Introduction}

Until recently, consideration of transport problems were mainly concrete in traffic studies in which only considered a mechanized mobility strictly limited to the car and its needs. Recent legislative developments bring the consideration of all networks, with special emphasis on the footpaths and cycle lanes, and the need to give adequate response to those new activities locations not based on an access mainly intended for private vehicles.

Along these lines, we are witnessing new rules where Catalonia became in 2003 the first Autonomous Community equipped with a law of motion. The norm includes a broad reference to sustainable mobility and, in fact, was born with the main objective of "giving priority to public transport" to the detriment of the car. The law makes the urban development conditional on mobility; so that, it cannot be approved any development project if it does not have a study of traffic volume generated.

The change of mobility model promoted by this law (Law 9/2003, June 13th, of mobility), pursues the new mobility needs are solved through greater use of more sustainable means of transport. Other regional laws on the same line have recently joined, in Navarra, Valencia and Basque Country.

In September 2009, the European Union adopted the Action Plan on Urban Mobility, where twenty concrete measures to execute in the following four years are proposed, to help national, regional and local authorities to achieve the objectives of sustainable urban mobility. The Action Plan concrete proposals in the Green Paper on Urban Mobility adopted on 25th September 2007.

The Plan picked up a package of measures in different areas of very different orientation, among other: accelerating the spread of sustainable urban mobility plans (SUMP), improving information on travel Intelligent Transport Systems (ITS) for urban mobility, improve data and statistics, optimize existing sources of funding, creation of an urban mobility observatory, coordination of policies for sustainable urban mobility and regional policies and improving accessibility for people with disabilities.

As provided in article 9 of the Mobility Law of Valencia (Law 6/2011, April 11 th, of Mobility of Valencian Generalitat), mobility plans are the instruments that specify the gradual progress towards more balanced mobility patterns, with increasing participation of non-motorized modes and public transport.

Programs and strategies for pedestrian and cyclist mobility of Valencia SUMP [1] have been prepared by a team of teachers and professionals related to the Polytechnic University of Valencia, in collaboration with Local Government, action developer, and IDOM and EPYPSA companies

\section{The structure of urban quality programs for pedestrians and cyclists}

As regards municipal Mobility Plans, Article 10 of Valencia Mobility Law determines that these documents include: an analysis of the essential parameters that define the mobility at the time they are formulated, the objectives in relation 
to its medium and long term, and those determinations necessary to achieve those objectives.

Also mobility plans settings extend to "design and dimensioning of road and public transport networks, specific infrastructure for pedestrians and cyclists, the parking system and relevant aspects of urban planning when they establish quantitative and qualitative aspects of transport demand such as urban densities, activities integration, amenities location and other common facilities that attract transportation".

In summary and according to the Guide for development and implementation of Sustainable Urban Mobility Plans [2] the execution of a sustainable mobility plan should generally include a previous phase of global analysis and diagnosis, collecting data on mobility that will originate the phase of defining strategies, proposals and concrete measures for improvement, contained in the plan document. Having overcome both phases of the process, a period of public participation is open besides the search of the necessary funding to enable its implementation, monitoring and subsequent evaluation, with the establishment of those opportune corrective measures.

Consequently, the technical document of SUMP, at formal level, is structured into two volumes: diagnostic and actions and measures, and the latter collects the policies that should cover the major objectives of SUMP, including Recovery of Urban Quality Plans, where programs for pedestrians and cyclists are framed. In most plans written so far, the Recovery Urban Plan Quality and Accessibility Plan for people with disabilities, merge into one.

Urban Quality Plans contain programs or projects aimed at promoting nonmotorized modes, creating main pedestrian routes and residential core areas with traffic calming and itineraries for cyclists with bike rental.

\subsection{Pedestrian and cyclist mobility diagnosis}

A good diagnosis should analyze all the factors that influence pedestrian and cyclist movements: the territorial and urban growth model, topography, barriers for pedestrian and cyclist as the railway and the main road infrastructure and natural barriers as channels, and other artificial obstacles.

Focused on the features of pedestrian mobility, we should scrutinize the modal share, resulting from the mobility survey to be issued for a sufficiently representative sample of all social strata population; through it we obtain statistics on the frequency of the number of trips, the ratio number of trips/ motive, number of trips / type of resident, and traffic accidents percentage.

The diagnosis must also consider obtaining indicators for mobility on foot: the average travel time on foot, speed, age, time travel distribution and touristic mobility; as well as knowledge of current demand of space for pedestrian and cyclist from gauging measurement (index pedestrian / street width) and detection of problems regarding claims, danger, infrastructure, new developments, etc.

It should analyze the existing pedestrian infrastructure, considering aspects such as the length and area of the network and pedestrian pathways and surfaces for pedestrian-only spaces. The type of streets will be collected in an inventory: pedestrian-only and pedestrian priority roads, roads in coexistence, pedestrian 
priority roads with restricted traffic (ACIRE zones, in Córdoba [3]), roads with sufficient section for shared use pedestrian / motor vehicle / bike, roads with low width of sidewalk, commercial and equipment attractive areas and pedestrian and cyclists existing routes.

The accessibility plan to historical district should be subject to independent analysis, in which we study hierarchy main routes, itineraries and neighborhood walks, and possible options for pedestrianize and restricting access to residents and loading and unloading vehicles, as in the case of the city of León [4], or the study of scooters and minibus mobility in the old quarter of Segovia [5].

Another aspect that should concern the assessment phase is the urban planning and sustainability indications from the town plans, landscape plans, traffic plans, etc., that are targeted for the municipality.

Different analyzes have contributed to the debate on densities and mobility, analyzing population densities and jobs in several cities. Recent research has shown a statistically significant relationship between various definitions of urban density and the percentage of pedestrian trips made in different districts and towns of the metropolitan area of Madrid, showing that a higher density greater proportion of walking trips in the modal split (Pozueta et al. [6]).

The figures obtained show a strong increase in the consumption of gasoline in the section below 30-40 people+current jobs/hectare, precise intensities that make less viable public transport operations and more attractive non-motorized transportation (Newman and Kenworthy [7]).

When the urban model is based on single-function areas, intended just as a dominant activity, the distances between different uses are increased at the expense of non-motorized movement. The combination of low density and single-function translates not only the need for motorized vehicles, but also unable to provide adequate public transport services; adequate in perception of travellers (frequency, comfort, schedules) and also in the collective assessment of them.

It aims to create proximity between activities and housing, in combination with the compactness, the demand for motorized transport is reduced. To this end it is necessary to introduce in urban planning methods and standards to ensure the complexity and mix of uses in the new development.

The importance of the city-planning design is proved in a previous study on pedestrian mobility in five new districts of Valencia City [8], we got the following results: The building density $(0.9 \mathrm{~m} 2 \mathrm{t} / \mathrm{m} 2 \mathrm{~s})$ approaches the maximum set by the planning legislation; block dimensions exceed $100 \mathrm{~m}$ in their perimeters side with areas of more than $10,000 \mathrm{~m} 2$; in the order of 70 to $80 \%$ of the total block area is released for private use, so the buildable area focus on 25$30 \%$ of the block and building heights are around 14 plants. The buildable commercial use is negligible with respect to the residential density, makes up $4 \%$ of the total buildable area of the sector.

The urban fabric is not permeable, block sizes exceeding $100 \mathrm{~m}$ on its flanks. There is no possibility of introducing walkways that fragment blocks because they are on private soil where sports facilities and gardens are located only accessible to the neighbours. 
Towers are open air buildings inside a big lot, their alignment is far from the street, and the entire block is surrounded by a fence with a single point of access to the complex. All this added to the lack of commercial premises on the ground floor or access points to homes and walks over 100 meters along parcels, make any movement on foot inhospitable and discourage.

\subsection{Proposals for improving the quality of urban space: a benchmarking of Spanish SUMPS}

Urban space quality programs propose specific objectives focus on increasing the weight of non-motorized modes, reducing natural and infrastructural barriers, insecurity and danger in public spaces and obtaining accessibility for people with disabilities.

These objectives will be achieved with proposals that are specified in the following:

In promoting of pedestrian mobility, we create a pedestrian network or scheme of continuous walkways or urban corridors, and we act on that network with the extension of sidewalks and pedestrian precincts, with raised crosswalks in minor roads, and traffic lights with high green phase for walkers in major roads with heavy traffic. In this network, we removed barriers for people with disabilities; we plan school itineraries with 20 and $30 \mathrm{Kmph}$-zones in their surroundings, and implement a plan of pedestrian signposting.

The promotion of mixed mobility pedestrian+bike, can be obtained through speed limit zones (30Kmph-zones and 20Kmph-zone), shared traffic areas or pedestrian priority areas, removing black points and planning pedestrian and cycle routes for leisure and recreation.

The improvement of pedestrian quality in old quarter, given its complex features obtained in the diagnostic phase, and the specific preservation rules for heritage environments, must consider, after its isolated study, a set of specific proposals to this area.

In a comparative study of SUMP proposal documents, which were elaborated in nine Spanish cities, from 2007 to 2013, we could find twelve general urban quality programs, related to improve the pedestrian and cyclists mobility. Not

Table 1: Urban quality improvement programs obtained from the nine Spanish SUMPS studied.

\begin{tabular}{|c|l|}
\hline $\begin{array}{l}\mathbf{N}^{\mathbf{0}} \\
\text { Prog. }\end{array}$ & Urban space quality improvement programs \\
\hline $\mathbf{1}$ & Main pedestrian itineraries project \\
\hline $\mathbf{2}$ & Urban centers with pedestrian priority and traffic calm areas \\
\hline $\mathbf{3}$ & Accesibility promotion and barriers removal \\
\hline $\mathbf{4}$ & Improvement road safety plan/signposting \\
\hline $\mathbf{5}$ & Movility considerations in new developments \\
\hline $\mathbf{6}$ & Specific urban quality plan for historical district \\
\hline $\mathbf{7}$ & Main cycle routes plan \\
\hline $\mathbf{8}$ & Bike parking network \\
\hline $\mathbf{9}$ & Bike rental \\
\hline $\mathbf{1 0}$ & Cycle modal share improvement \\
\hline $\mathbf{1 1}$ & Pedestrian and cycle routes for leisure and recreation \\
\hline $\mathbf{1 2}$ & Bike use training \\
\hline
\end{tabular}


all of them are present in each city SUMP, but selected according to the city needs and features in terms of mobility. In table 2, we can compare the programs used as resource of sustainable mobility in each city, including Valencia, as part of the study, whose development we will see thoroughness.

Table 2: Comparative study on the different twelve urban quality improvement programs developed in nine Spanish SUMPS.

\begin{tabular}{|c|c|c|c|c|c|c|c|c|c|}
\hline $\begin{array}{l}\mathbf{N}^{\circ} \\
\text { Prog. }\end{array}$ & $\begin{array}{c}\text { Getafe } \\
2007\end{array}$ & $\begin{array}{l}\text { Pinto } \\
2008\end{array}$ & $\begin{array}{c}\text { Segovia } \\
2008\end{array}$ & $\begin{array}{l}\text { León } \\
2009\end{array}$ & $\begin{array}{l}\text { Irún } \\
2010\end{array}$ & $\begin{array}{c}\text { Córdoba } \\
2011\end{array}$ & $\begin{array}{c}\text { Salamanca } \\
2011\end{array}$ & $\begin{array}{c}\text { Granada } \\
2013\end{array}$ & $\begin{array}{c}\text { Valencia } \\
2013\end{array}$ \\
\hline 1 & $\mathrm{x}$ & $\mathrm{x}$ & $\mathrm{x}$ & $\mathrm{x}$ & $\mathrm{x}$ & $\mathrm{x}$ & & $\mathrm{x}$ & $\mathrm{x}$ \\
\hline 2 & $x$ & $x$ & $\mathrm{x}$ & $\mathrm{x}$ & $\frac{x}{x}$ & $\mathrm{x}$ & $\mathrm{x}$ & $x$ & $\mathrm{x}$ \\
\hline 3 & $x$ & $x$ & $x$ & & $\bar{x}$ & $x$ & $x$ & $x$ & $x$ \\
\hline 4 & $x$ & & & $x$ & $x$ & $x$ & $x$ & $x$ & $x$ \\
\hline 5 & & & $\mathrm{x}$ & & & $x$ & & & \\
\hline 6 & & & $\mathrm{x}$ & & & $\mathrm{x}$ & $\mathrm{x}$ & & $\mathrm{x}$ \\
\hline 7 & $\mathrm{x}$ & $\mathrm{x}$ & & & $\mathrm{x}$ & $x$ & $\mathrm{x}$ & $\mathrm{x}$ & $\mathrm{x}$ \\
\hline 8 & $x$ & $x$ & & & $\bar{x}$ & & & $x$ & $x$ \\
\hline 9 & $x$ & $x$ & & & $x$ & $\bar{x}$ & $x$ & & $\mathrm{x}$ \\
\hline 10 & & & & & & & & & \\
\hline & $\mathrm{x}$ & $\mathrm{x}$ & & & $x$ & $\mathrm{x}$ & & $\mathrm{x}$ & $x$ \\
\hline 11 & $\mathrm{x}$ & & & $\mathrm{x}$ & $\mathrm{x}$ & & $\mathrm{x}$ & $\mathrm{x}$ & $\mathrm{x}$ \\
\hline 12 & $\mathrm{x}$ & & & & & & & $\mathrm{x}$ & \\
\hline
\end{tabular}

Table 3: Comparative study on the different proposes to manage the car traffic reduction in historical districts.

\begin{tabular}{|c|c|c|c|c|}
\hline & & rogram 6. Specific urban quality $p$ & Dans for historical districts in. & \\
\hline Topics & $\begin{array}{c}\text { Segovia } \\
\end{array}$ & Córdoba & Salamanca & $\begin{array}{l}\text { Valencia } \\
\end{array}$ \\
\hline \multirow{8}{*}{$\begin{array}{l}\text { Pedestrian and urban } \\
\text { quality }\end{array}$} & New cross section & New cross section & New cross section & New cross section \\
\hline & New pedestrian areas & New pedestrian areas & New pedestrian areas & New pedestrian areas \\
\hline & & ACIRE zones & $30 \mathrm{Kmph}-z o n e s$ & $30 \mathrm{Kmph}-z o n e s$ \\
\hline & & & & traffic reduction plan \\
\hline & Shared traffic axis & Pedestrian itineraris network & & \\
\hline & Access restriction & Freight transport restriction & Access restriction & Access reduction \\
\hline & Not intrusive signposting & & & \\
\hline & & Loading and unloading time limit & & \\
\hline \multirow{4}{*}{ Car parks } & Neighbours car parks & & & Neighbours car parks \\
\hline & & Rate zones & & \\
\hline & & Hotels car parks management & & \\
\hline & & Dissuasive car parks & & \\
\hline Public transportation & Electric minibuses & & & \\
\hline \multirow{3}{*}{ Cycle movility } & Main cycle route & Cycle routes network & Cycle routes network & \\
\hline & Points of bike park and rental & & Points of bike park and rental & Points of bike park and rental \\
\hline & & & & Bike moda \\
\hline
\end{tabular}

In those cities where the historical district has a separated treatment with a specific urban quality plan (Segovia, Córdoba, Salamanca [9] and Valencia), the resources to develop are varied, depending on old quarter dimensions, morphology and resident population. In the same study we have compared in table 3 different proposed objectives to manage the car traffic reduction in these areas.

With the comparison below we can better locate Valencia's following described experiences in a wider context and sketch a generalized approach. 


\section{Proposals for pedestrian mobility in SUMP of Valencia}

The works proposed in the SUMP of the Valencia City, with a medium-term horizon, seek a progressive framework for the city as an exclusive pedestrian network with optimal development, based on the configuration of consecutive stages: starting with the creation of shared ways or enlarged sidewalks in several streets, that later give way to routes for pedestrian exclusive use.

The aim is to set finished and continuous walkways, able to connect different neighborhoods, and serve as burgeoning passages for existing commercial areas. Complementarily, the action looks at specific neighborhoods for creating neighborhood axes as reinforcing centrality elements, where progressively through-traffic is moved to back streets leaving free space for public gardens, play grounds and other amenities.

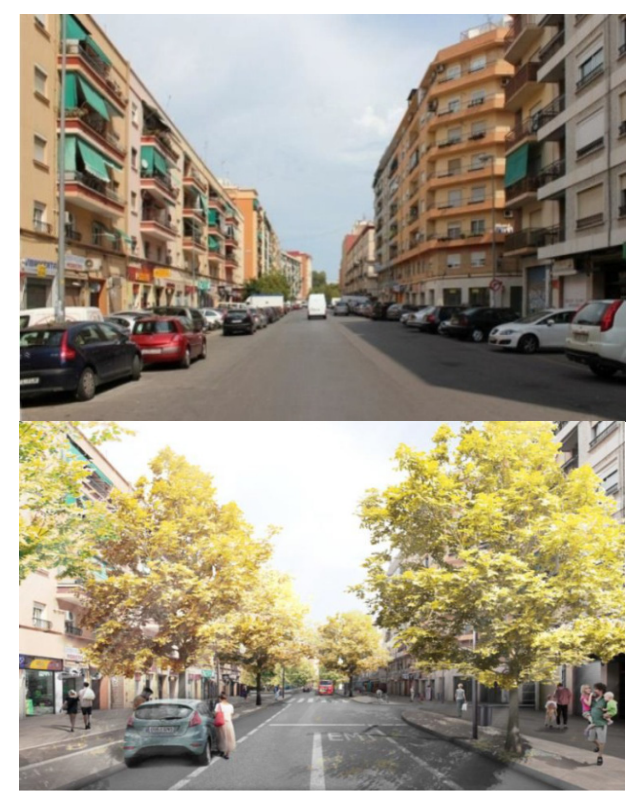

Figure 1: Main Pedestrian Route (IPP_02) along Ramiro de Maeztu Street (Valencia). Present situation and urban design below. Valencia SUMP, 2013.

\subsection{Speed limitation zones}

These actions are intended to control speed based on a limitation of 50Kmph and two possibilities for greater restriction: $30 \mathrm{Kmph}-z o n e s$ in residential and business areas, back streets and adjacent traffic areas, 20Kmph-zone in residential areas or shared traffic streets, and even 10Kmph-zones may be added in shared traffic areas with pedestrian priority. 
These areas have a length between $200 \mathrm{~m}$ and $1.8-2 \mathrm{~km}$ of maximum extension that must not be exceeded, above which the speed and the risk of accident increase.

Considering these criteria we demarcate local areas out of the main traffic routes, so that such prior consideration precedes subsequent redevelopment and pedestrian tasks in some of the sections. The street design adopts the criterion of French CEREMA [10], without restrictions for walkers that can cross the street at any point without crosswalks.

\subsection{Superblocks}

The proposal lies in the coordination of different transport networks and the streets specialization in two types of routes: the basic network traffic (perimeter) as support of main traffic and streets inside superblocks, restricted to through traffic for neighbors access and cargo handling with limited speed, and for the development of the rest of activities. The superblocks structure allows, in consolidated fabrics, rebalance spaces allocated to different uses, with the release of up to $70 \%$ of public space for activities on the street.

This is the project of a network of basic ways the most orthogonal as possible, with crosses about every 400 meters, where motorized transport travels (private car and public transportation), with ways within superblocks without differentiation between driveway and sidewalk.

In the current phase of SUMP, the objective is to analyze the consequences of a closed design prior to its implementation, however, it might be appropriate a gradual introduction to the Examples of Valencia, of regular frame, medium density and important commercial offer (although not exclusively), in the neighborhoods of Gran Via, Russafa, Arrancapins and the Petxina; and parts of Cabanyal.

\subsection{The structural corridors}

The proposed pedestrian routes are divided into six major radial axes that converge in the old quarter of the city, along with another ring way, that originate longitudinal axes of attraction that encourage and attract strollers on the move, who can use them in part of their walks, without go over them entirely.

The hierarchy of routes networks follows this structure:

Main pedestrian routes (IPP): they develop through radial routes that originate in old quarter to beltway, where it joins the pedestrian-cyclist mesh of Strategic Infrastructure Plan.

Side pedestrian routes (IPS): they run specific sectors of the city.

Radial (IPSR): they link attraction centers in every neighborhood with their immediate surroundings. Their users are residents moving on foot to the local facilities.

Ringed (IPSA): they link pedestrian areas in different neighborhoods.

The pedestrian network covers the entire urban area; the itineraries are continuous, without barriers, and they properly connect the different activities (home, work centers, schools, shopping areas, etc.). Besides, they are supported 
by public facilities, rest areas and attraction centers for pedestrians. Each itinerary is described through an index card where it appears: origin-destination, length and proposed cross section as well as pedestrian attraction areas and the sections between them.

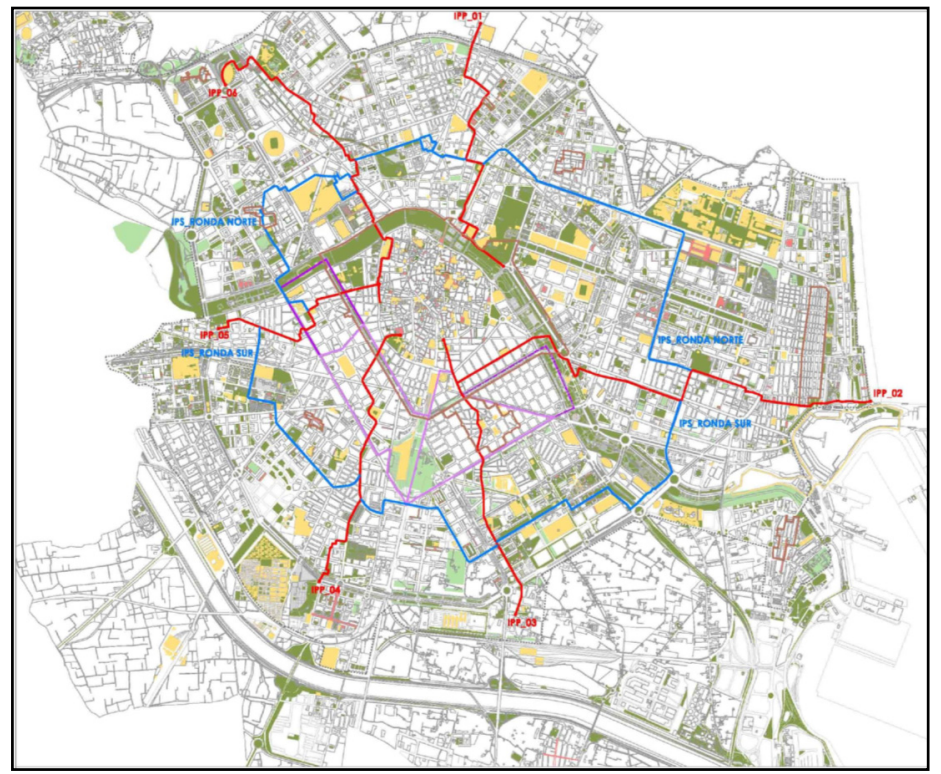

Figure 2: Structural corridors proposed in Valencia. Plane PRO_PEA_03 of Valencia SUMP, 2013.

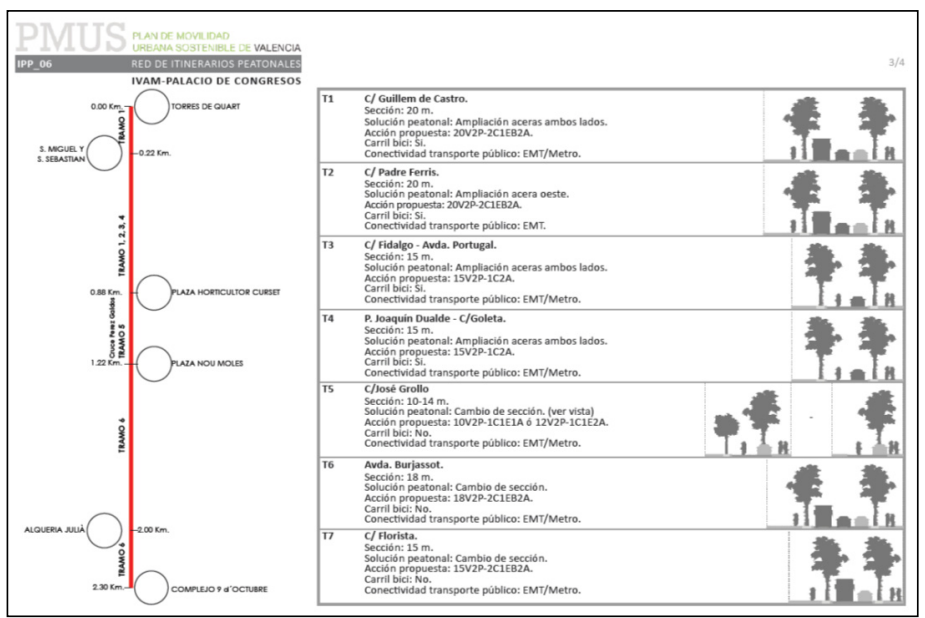

Figure 3: Description index card for IPP-06 itinerary of Valencia SUMP, with description of each route section. 


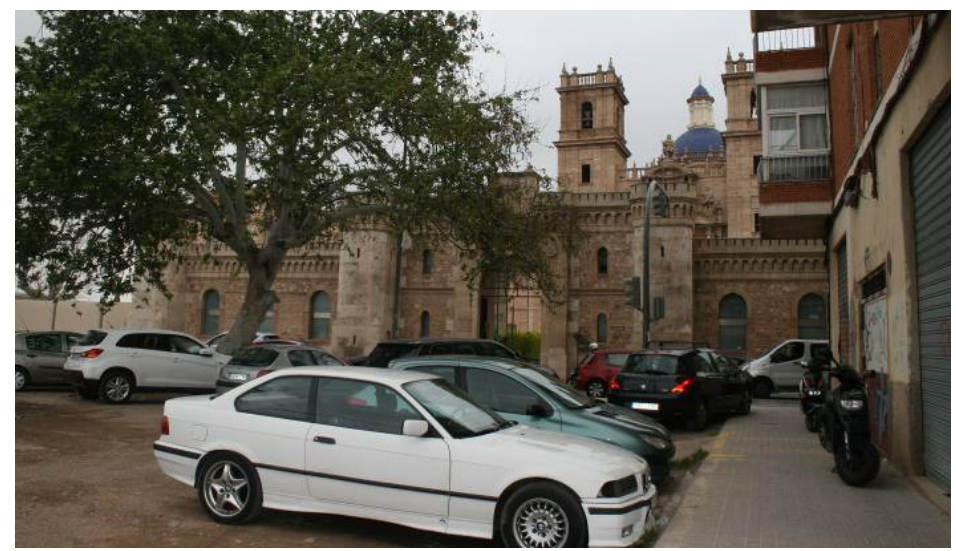

Figure 4: Monastery of San Miguel de los Reyes (Valencia), example of heritage site without a good pedestrian access.

Besides, the purpose of the previous study was to evaluate the possible interest of including cultural heritage elements in the layout of the pedestrian network and ponder whether it constitutes a real attraction for a pedestrian.

Using this monuments as main sites in pedestrian routes, we get the enhancement of this constructions with historical and heritage value: on the one hand their accessibility improvement as well as their promotion and advertising, what would contribute to sightseeing increasing with consequent impact on the local economy; otherwise, dissemination and knowledge of these goods in the Valencian society is an argument that does not require too many explanations. Made to give examples of buildings of heritage significance without a good pedestrian access, we could cite the Museum of History of the City, the Museum of San Pío V, and the Monastery of San Miguel de los Reyes.

\subsection{Intervention in old quarter of Valencia}

We know the old district is the appropriate context for pedestrian given by a highly populated area, whose inhabitants use the facilities located near your home, accessing them on foot, and find in the public space of the neighbourhood the ideal location to enjoy their leisure.

However, this ideal context is not the one of Valencia center; one of the most remarkable factors of unsustainability is the strong presence of motorized vehicles driving through streets and squares that were not designed to this unbearable situation.

There are many actions that have taken place in the center in order to improve the pedestrian presence, and there are many pedestrian streets or pedestrian priority spaces, however, probably because of excessive permissiveness with cars that invade these areas, there is not a real pedestrian route in the historic center, even a promenade or a completely pedestrian precinct. The performances 
in favor of pedestrians must be strongly against the presence of drivers; prosecute and punish infractions, prevent visitors parking with policies to hinder access and parking in the center, are preliminary and necessary decisions to create pedestrian zones.

Moreover, the historic city should not fail to appear attractive to the foreign visitor, for tourists who want to explore the city and its historical and cultural landmarks places. Tourists prefer and enjoy the pedestrian street; meanwhile pedestrian streets are favored by presence of tourists.

Unquestionably, the old quarters of cities have an element with respect to any other area that should make a noticeable difference when establishing possible attractive to pedestrian traffic: the presence of heritage sites gives the public space an added interest.

Considering previous observations, the performances in the historic city, presents in the SUMP, set out a partial pedestrianization, with the transformation of roads in single platform; the new type of longitudinal section, will be adapted to the width of street, less than $7 \mathrm{~m}$, above $7 \mathrm{~m}$ or $9 \mathrm{~m}$ with through-traffic when necessary.

All this is complemented with actions to recover the urban space of historic squares, whose current use as road parking turn them into waste space and barriers for pedestrians, in the worst case.

The areas of special preservation for its heritage character, as the surroundings of the Silk Market, World Heritage Monument, Central Market, Town Hall Square and Queen Square, are marked as priority interventions of full pedestrianization.

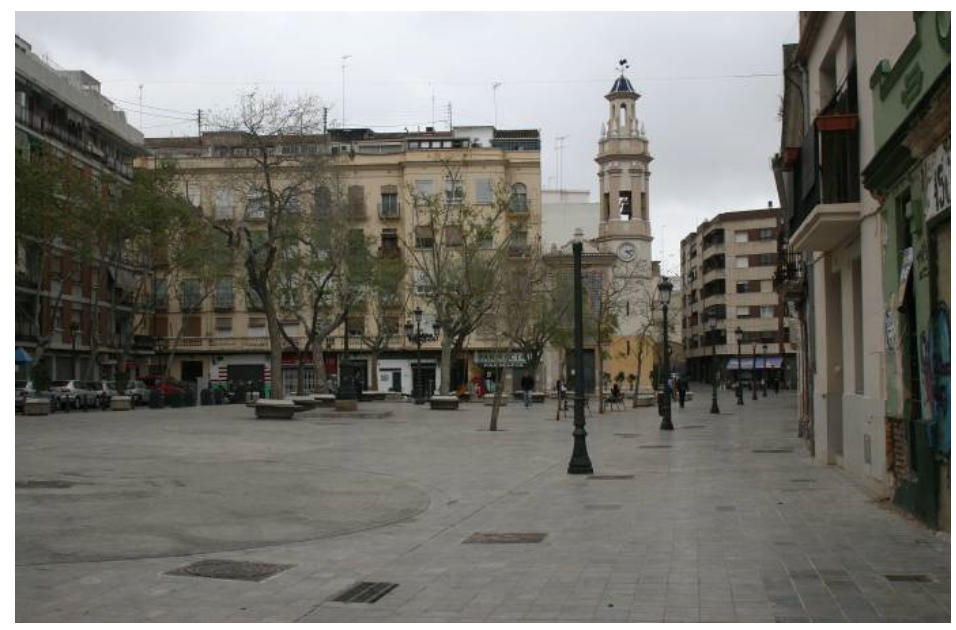

Figure 5: Works for increasing pedestrian areas in Valencia old districts. Patraix Square, 2012. 


\section{Conclusions}

In conclusion, we can contribute the Urban Quality Improvement Plan of Valencia SUMP, with proposals and programs for pedestrian intervention in Valencia City, has the intention to resolve important aspects for urban regeneration city, in the interests of sustainability, of improvement of quality of life, citizen security and people integration. As the public participation plan demonstrates, this subject interests citizens, concerned that the investment objectives of the local government will be set aside for improving quality of their city, in terms of environmental progress, resources savings and the creation of economic and tourism assets that activate employment.

\section{References}

[1] Sustainable Urban Mobility Plan of Valencia, Valencia Local Council, Spain, 2013, online. www.pmus-valencia.com

[2] Guide for development and implementation of Sustainable Urban Mobility Plans; TRANSyT, Transportation Research Center of the Polytechnic University of Madrid, Ministry of Development, Environment, Industry, Tourism and Trade, IDEA, Spanish Federation of Municipalities and Provinces and Regional Transport Consortium of Madrid, 2006.

[3] Sustainable Urban Mobility Plan of Córdoba, Córdoba Local Council, Spain, 2011, online. www.plandemovilidadcordoba.es

[4] Sustainable Urban Mobility Plan of León, León Local Council, Spain, 2009, online. www.aytoleon.es/es/ayuntamiento/areasmunicipales/ urbanismo/Documents/Plan_Director_PMUS_Leon.pdf

[5] Sustainable Urban Mobility Plan of Segovia, Segovia Local Council, Spain, 2008, online.www.segovia.es/index.php/mod.pags/mem.detalle/ id.11335/relcategoria.2585/area.23/seccion.38

[6] Pozueta, J. \& Lamíquiz, F., Porto, M., La ciudad paseable, CEDEX. Ministry of Development. Madrid, 2009.

[7] Newman, P. \& Kenworthy, J.; Urban Design to Reduce Automobile Dependence, International Journal of Suburban and Metropolitan Studies, 2(1), pp. 37-48, 2006.

[8] Cayuela, A., Broseta, M.T., et al. Los factores de caraterización de la movilidad sostenible en los diferentes barrios de Valencia, Cátedra Ciudad de Valencia, Universidad Politécnica de Valencia, 2012.

[9] Sustainable Urban Mobility Plan of Salamanca, Salamenca Local Council, Spain, 2011, online. www.mecsa.es/salamanca/

[10] Centre d'Etudes et d'expertise sur les risques, l'environnement, the mobilité et l'aménagement, Direction Technique et Territoires Ville, France. www.cerema.fr/mobilite-r5.html 